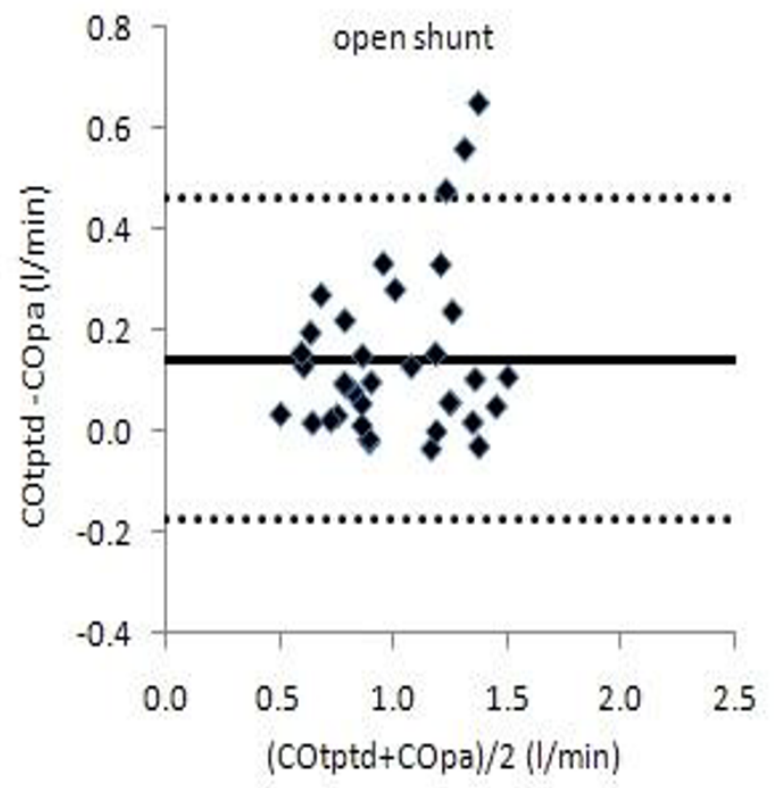

[Bland Altman plot open shunt]

210

\section{CEREBRAL AND SYSTEMIC OXIMETRY USING NEAR-INFRARED SPECTROSCOPY IN MANAGEMENT OF CONGENITAL CARDIAC POSTOPERATIVE PERIOD}

M.I. Pescador Chamorro, M. González-Valcárcel

Espinosa, C. Herbozo Nory, D. Blanco Bravo,

S. Caballero Martín, M. Sánchez Luna

Hospital General Universitario Gregorio Marañón, Madrid, Spain

Introduction: Near infrared spectroscopy allows non-invasive assessment of cerebral and systemic oxygen saturation on the management of congenital cardiac surgery.

Objectives: To know the median values of oxygen cerebral and systemic in newborns who undergo cardiac surgery.

Materials and methods: Observational prospective study from June 2009 to February 2010. The studied variables were gestational age, type of congenital heart disease, inotropical support, mean arterial pressure, oxygen extraction, cerebral and systemic oxygen saturation, central venous pressure, left atrial pressure, diuresis, level of lactate, oxygen saturation, FiO2, postoperative complications and need for extracorporeal membrane oxygenation (ECMO).
Results: 22 patients were studied. Transposition of great arteries was the most frequent cardiac disease, median gestational age was $38+4$ weeks. Mean values of cerebral saturation was $62 \% \pm 9 \%$ and systemic saturation $59 \% \pm 14 \%$. Median values for the variables were: median blood pressure 49,9 $\pm 4 \mathrm{mmHg}$; oxygen extraction $40 \pm 11$; lactate 2,3 $\pm 1 \mathrm{mmol} / \mathrm{L} ;$ paO2 $72 \pm 9 \mathrm{mmHg} ; \mathrm{FiO} 237 \pm 13 \%$; central venous pressure $7 \pm 2 \mathrm{mmHg}$; left atrial pressure $6 \pm 3 \mathrm{mmHg}$. Dopamine being used in all cases at $8 \mathrm{mcg} / \mathrm{kg} / \mathrm{min}$ and milrinone in 21 cases at $0,9 \mathrm{mcg} / \mathrm{kg} / \mathrm{min}$. Epinephrine was used in 17 at $0,08 \mathrm{mcg} / \mathrm{kg} / \mathrm{min}$. In 21 cases furosemide was used at $0,65 \mathrm{mg} / \mathrm{kg} / \mathrm{hr}$, with diuresis of $4,9 \mathrm{~mL} / \mathrm{Kg} / \mathrm{hr}$. Five required $\mathrm{ECMO}$.

Conclusions: Cerebral and systemic oxygen saturation supplies easily acquired data that provides information on the haemodinamical situation in the postoperative neonatal cardiac surgery. It is of special importance to consider the tendency of the values thanks to its continue recording.

\section{1}

EXPRESSION OF NO SYNTHASES AND REDOX ENZYMES IN UMBILICAL ARTERIES FROM NEWBORNS BORN SMALL, APPROPRIATE, AND LARGE FOR GESTATIONAL AGE

\author{
U. Zillessen ${ }^{1}, \mathrm{H}$. Li ${ }^{2}$, E. Mildenberger ${ }^{1}$ \\ ${ }^{1}$ Neonatology, Zentrum für Kinder- und \\ Jugendmedizin, ${ }^{2}$ Pharmacology, Johannes \\ Gutenberg-Universität Mainz, Mainz, Germany
}

Background: Modified expression of NO synthases and prooxidative and antioxidative enzymes accompany endothelial dysfunction, the first stage of atherosclerosis. Humans born small (SGA) and large (LGA) for gestational age are at higher risk to develop atherosclerosis later in life than humans born appropriate (AGA) for gestational age. We hypothesized that indicators of endothelial dysfunction could be detectable already at birth.

Aims: To find out whether the expression patterns of NO synthases (eNOS, iNOS, nNOS), of prooxidative enzymes (components of NADPH oxidases, NOX1, NOX2, p22phox, p47phox), and of antioxidative enzymes (superoxide dismutase 1,2 , and 3 , catalase, gluthation peroxidase 1) in umbilical arteries differ between SGA, LGA, and AGA newborns.

Methods: Protein expression was determined by Western blotting in homogenisated samples of 